Article

\title{
Hippeastrum reticulatum (Amaryllidaceae): Alkaloid Profiling, Biological Activities and Molecular Docking
}

\author{
Luciana R. Tallini ${ }^{1}{ }^{(D}$, Edison H. Osorio ${ }^{2}$, Vanessa Dias dos Santos ${ }^{3}$, Warley de Souza Borges ${ }^{3}$, \\ Marcel Kaiser ${ }^{4,5}$, Francesc Viladomat ${ }^{1}$, José Angelo S. Zuanazzi ${ }^{6}{ }^{(0)}$ and Jaume Bastida ${ }^{1, *}$ \\ 1 Group of Natural Products, Faculty of Pharmacy, University of Barcelona, Av. Joan XXIII, 27-31, \\ 08028-Barcelona, Spain; lucianatallini@gmail.com (L.R.T.); fviladomat@ub.edu (F.V.) \\ 2 Department of Basic Sciences, Catholic University Luis Amigó, SISCO, Transversal 51 A No. 67B-90, \\ Medellín, Colombia; edison.osorio@gmail.com \\ 3 Department of Chemistry, Federal University of Espírito Santo, Av. Fernando Ferrari 514, \\ 29075-915 Vitória ES, Brazil; vanessadds@yahoo.com.br (V.D.d.S.); warley.borges@ufes.br (W.d.S.B.) \\ 4 Medicinal Parasitology and Infection Biology, Swiss Tropical Institute, Socinstrasse 57, \\ 4051 Basel, Switzerland; marcel.kaiser@unibas.ch \\ 5 University of Basel, Petersplatz 1, 4001 Basel, Switzerland \\ 6 Faculty of Pharmacy, Federal University of Rio Grande do Sul, Av. Ipiranga 2752, \\ 90610-000 Porto Alegre RS, Brazil; zuanazzi@ufrgs.br \\ * Correspondence: jaumebastida@ub.edu; Tel.: +34-934-020-268
}

Received: 24 October 2017; Accepted: 7 December 2017; Published: 9 December 2017

\begin{abstract}
The Amaryllidaceae family has proven to be a rich source of active compounds, which are characterized by unique skeleton arrangements and a broad spectrum of biological activities. The aim of this work was to perform the first detailed study of the alkaloid constituents of Hippeastrum reticulatum (Amaryllidaceae) and to determine the anti-parasitological and cholinesterase (AChE and $\mathrm{BuChE}$ ) inhibitory activities of the epimers ( $6 \alpha$-hydroxymaritidine and $6 \beta$-hydroxymaritidine). Twelve alkaloids were identified in $H$. reticulatum: eight known alkaloids by GC-MS and four unknown ( $6 \alpha$-hydroxymaritidine, $6 \beta$-hydroxymaritidine, reticulinine and isoreticulinine) by NMR. The epimer mixture ( $6 \alpha$-hydroxymaritidine and $6 \beta$-hydroxymaritidine) showed low activity against all protozoan parasites tested and weak AChE-inhibitory activity. Finally, a molecular docking analysis of $\mathrm{AChE}$ and $\mathrm{BuChE}$ proteins showed that isoreticulinine may be classified as a potential inhibitory molecule since it can be stabilized in the active site through hydrogen bonds, $\pi-\pi$ stacking and hydrophobic interactions.
\end{abstract}

Keywords: $6 \alpha$-hydroxymaritidine; $6 \beta$-hydroxymaritidine; reticulinine; isoreticulinine; Hippeastrum reticulatum

\section{Introduction}

Natural products offer a wealth of bio-structural information that can be used to guide drug discovery and molecular design projects [1]. Plants have played a huge role in traditional medicine, and plant screening has become an important tool in drug discovery for pharmaceutical companies and university institutes [2]. Alkaloids are plant secondary metabolites that are usually low in nitrogen but high in oxygen [3]. Their three-dimensional complexity and interesting ring systems are of great interest for drug development [3-5].

The Amaryllidaceae, a plant family in the monocot order Asparagales, is composed of three subfamilies: Amaryllidoideae, Agapanthoideae and Allioideae [6,7]. The Amaryllidoideae include about 80 genera [8] that are mainly distributed in tropical and subtropical regions, but also in temperate 
zones [9]. A particular feature of plants of the Amaryllidoideae subfamily is their content of an exclusive, numerous and still expanding group of alkaloids, known as Amaryllidaceae alkaloids. These compounds are characterized by unique skeleton arrangements and a broad spectrum of biological activities [10]. Galanthamine is the most important Amaryllidaceae alkaloid, having received FDA approval in 2001 for the clinical management of mild to moderate Alzheimer's disease (AD) [11].

Over 47 million people worldwide were living with dementia in 2016, a figure expected to increase to 131 million by 2050 [12]. The most common symptom of AD is a deterioration of memory and other cognitive domains, leading to death within 3 to 9 years after diagnosis [13]. Multiple factors have been implicated in AD pathology, including a reduced cholinergic neurotransmission level, oxidative stress and aggregated amyloid- $\beta$-peptide $(\mathrm{A} \beta)$ [14].

Another global health challenge is tackling the neglected tropical diseases (NTDs), a diverse group of communicable diseases that prevail in tropical and subtropical conditions and affect more than a billion people [15]. The World Health Organization (WHO) lists 17 NTDs, including Chagas disease, human African trypanosomiasis (sleeping sickness) and leishmaniosis. Alongside malaria, these diseases are highly feared in affected populations, where poverty limits access to prevention and treatment interventions [15]. One of the main reasons why these diseases are "neglected" is that there is little incentive for the pharmaceutical industry to invest in developing drugs for a patient population that cannot afford them [16]. Consequently, much of the research on effective treatment of these diseases is carried out in academic laboratories with limited financial, personnel, and technical resources [16].

The Hippeastrum Herb. is a genus (Amaryllidaceae) native to South America and comprises approximately 60 species [17], about 30 of which are found in Brazil; the majority are endemic and poorly studied [18]. This genus has been traditionally used to cure piles, tumors and various inflammatory disorders such as asthma [19]. Physiological activities reported for plants of this genus include psychopharmacological [20], against Trichomonas vaginalis [21] and cytotoxicity [22,23]. The species $\mathrm{H}$. reticulatum is widely used as an ornamental plant due to its colorful flowers ranging from light pink to dark purple [24]. In recent years, some studies have been published about its primary metabolites, pigment constituents (anthocyanins), botanical characterization, karyotypes and phylogenesis [9,24-26].

The aim of this work was to perform the first study of the alkaloid profile and biological activities of Hippeastrum reticulatum. Four new alkaloids were isolated and chemically characterized by spectroscopic methods and eight known alkaloids were identified by gas chromatography-mass spectrometry (GC-MS). Anti-parasitological and cholinesterase-acetylcholinesterase (AChE) and butyrylcholinesterase $(\mathrm{BuChE}$ )-inhibitory activities of the epimers (compounds 1 and 2, Figure 1) are described. Molecular docking studies were also carried out to investigate the affinity of the four new compounds for the active sites of $\mathrm{AChE}$ and $\mathrm{BuChE}$ based on intermolecular features such as hydrogen bonds, $\pi-\pi$ stacking and hydrophobic interactions. Unfortunately, it was not possible to determine the biological activities of the isomers (compounds 3 and 4, Figure 1) due to a lack of samples.

\section{Results and Discussion}

\subsection{Alkaloid Identification by GC-MS}

The $\mathrm{MeOH}$ extracts of $\mathrm{H}$. reticulatum plants were fractioned following the sequence described in the Experimental section. The fractions were analyzed and the structural types of the alkaloids from this species were identified by comparing their GC-MS spectra and Kovats Retention Index (RI) values with those of authentic Amaryllidaceae alkaloids previously isolated and identified by spectrometric methods (NMR, UV, CD, IR, MS) in our laboratory, by the NIST 05 Database or by literature data (Table 1). Eight known alkaloids were identified by GC-MS using our Amaryllidaceae alkaloid library (Figure 1) and four new alkaloids (1-4) were isolated and chemically characterized by spectroscopic methods. 
Table 1. Alkaloids identified in $H$. reticulatum by GC-MS.

\begin{tabular}{|c|c|c|c|}
\hline alkaloid & RI & $\mathbf{M}^{+}$ & MS \\
\hline galanthamine (11) & 2410.8 & $287(84)$ & $\begin{array}{l}288(20), 286(100), 270(15), 244(27) \\
230(15), 216(37), 174(32), 159(11), 115(16)\end{array}$ \\
\hline sanguinine (12) & 2430.5 & $273(100)$ & $\begin{array}{l}274(16), 272(77), 256(23), 202(31), 197(15), \\
165 \text { (14) } 160(45), 152(15), 115(19)\end{array}$ \\
\hline $\begin{array}{l}6 \beta \text { - and } 6 \alpha \text {-hydroxymaritidine }(1) \\
\text { and (2) }\end{array}$ & 2495.5 & $303(20)$ & $\begin{array}{l}286(9), 274(12), 260(21), 259(100), 258(12), \\
256(20), 241(30) 128(16), 115(20)\end{array}$ \\
\hline 8-O-demethylmaritidine (6) & 2522.4 & $273(100)$ & $\begin{array}{l}274(18), 230(24), 203(19), 202(25), 201(89), \\
189(55), 175(23), 115(19), 56(20)\end{array}$ \\
\hline maritidine (5) & 2528.5 & $287(100)$ & $\begin{array}{l}288(20), 244(35), 217(20) 216(25), 215(95), \\
203(55), 189(18), 128(17), 115(20)\end{array}$ \\
\hline 11,12-dehydroanhydrolycorine (10) & 2629.3 & $249(59)$ & $\begin{array}{l}248(100), 218(1), 190(26), 163(8), 137(1) \\
123(5), 95(13)\end{array}$ \\
\hline$m / z 264$ & 2693.6 & $265(76)$ & 264 (100), 248 (18), 220 (12), 191 (14),178 (18) \\
\hline 11-hydroxyvittatine (7) & 2732.5 & $287(5)$ & $\begin{array}{l}259(16), 258(100), 242(9), 214(9), 212(8) \\
211(13), 186(13), 181(14), 128(11)\end{array}$ \\
\hline lycorine (9) & 2771.8 & $287(18)$ & $\begin{array}{l}286(10), 268(19), 250(16), 238(7), 227(78) \\
226(100), 211(6), 147(5), 119(3)\end{array}$ \\
\hline isoreticulinine (4) & 2829.1 & $333(<1)$ & $\begin{array}{l}291(37), 290(100), 274(11), 272(6), 256(5), \\
228(5), 147(13)\end{array}$ \\
\hline reticulinine (3) & 2133.4 & $333(42)$ & $\begin{array}{l}332(100), 316(5) 290(6), 272(56), 256(31) \\
244(14), 216(14), 147(26)\end{array}$ \\
\hline$m / z 294$ & 2950.3 & $295(87)$ & $\begin{array}{l}294(100), 278(10), 264(3), 250(7), 235(3), \\
221(5), 207(3), 194(5)\end{array}$ \\
\hline$m / z 280$ & 2978.6 & $281(75)$ & $\begin{array}{l}280(100), 264(12), 250(3), 236(11), 219(4) \\
207(4), 194(8), 178(4), 167(3)\end{array}$ \\
\hline 2-methoxypratosine (8) & 3071.1 & $309(100)$ & $\begin{array}{l}310(20), 294(18), 284(7), 266(24), 251(14) \\
236(6), 164(4), 152(6)\end{array}$ \\
\hline
\end{tabular}

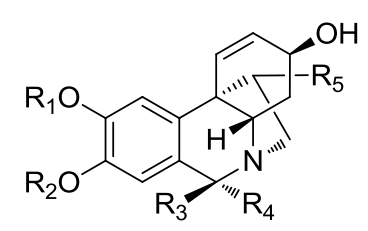

1; $\mathrm{R}_{1}=\mathrm{Me}, \mathrm{R}_{2}=\mathrm{Me}, \mathrm{R}_{3}=\mathrm{OH}, \mathrm{R}_{4}=\mathrm{H}, \mathrm{R}_{5}=\mathrm{H}$

2; $\mathrm{R}_{1}=\mathrm{Me}, \mathrm{R}_{2}=\mathrm{Me}, \mathrm{R}_{3}=\mathrm{H}, \mathrm{R}_{4}=\mathrm{OH}, \mathrm{R}_{5}=\mathrm{H}$

5; $\mathrm{R}_{1}=\mathrm{Me}, \mathrm{R}_{2}=\mathrm{Me}, \mathrm{R}_{3}=\mathrm{H}, \mathrm{R}_{4}=\mathrm{H}, \mathrm{R}_{5}=\mathrm{H}$

6; $\mathrm{R}_{1}=\mathrm{Me}, \mathrm{R}_{2}=\mathrm{H}, \mathrm{R}_{3}=\mathrm{H}, \mathrm{R}_{4}=\mathrm{H}, \mathrm{R}_{5}=\mathrm{H}$

7; $\mathrm{R}_{1}+\mathrm{R}_{2}=\mathrm{CH}_{2}, \mathrm{R}_{3}=\mathrm{H}, \mathrm{R}_{4}=\mathrm{H} ; \mathrm{R}_{5}=\mathrm{OH}$<smiles></smiles>

9<smiles>[R20]O[C@@H]1C[C@@H]2CCN3Cc4cc(O)c(OC)cc4[C@]2([C@@H]3O)[C@H]1O[R20]</smiles>

3; $\mathrm{R}_{1}=\mathrm{Ac}, \mathrm{R}_{2}=\mathrm{H}$

4; $\mathrm{R}_{1}=\mathrm{H}, \mathrm{R}_{2}=\mathrm{Ac}$<smiles>c1cc2c3c(c1)ccn3Cc1cc3c(cc1-2)OCO3</smiles>

10<smiles></smiles>

8<smiles>[R20]c1ccc2c3c1O[C@H]1C[C@@H](O)C=C[C@@]31CCN(C)C2</smiles>

11; $R_{1}=M e$ 12; $\mathrm{R}_{1}=\mathrm{H}$

Figure 1. Alkaloids identified in $H$. reticulatum. 


\subsection{Structural Elucidation by NMR}

\subsection{1. $6 \beta$-Hydroxymaritidine (1) and $6 \alpha$-hydroxymaritidine (2)}

Compounds $\mathbf{1}$ and $\mathbf{2}$ were obtained together from an acetate leaf fraction and isolated as a mixture, which was not separated by conventional chromatographic methods. The HRMS data of compounds 1 and 2 suggested the molecular formula $\mathrm{C}_{17} \mathrm{H}_{22} \mathrm{NO}_{4}$ for the parent ion $[\mathrm{M}+\mathrm{H}]^{+}$at $m / z 304.1544$ (calcd 304.1543). The absolute configuration of these epimers was determined by circular dichroism (CD). The curve and shape were qualitatively similar to those of known haemanthamine-type alkaloids, with the 5,10b-ethano bridge in an $\alpha$-orientation, having a minimum of $250 \mathrm{~nm}$ and a maximum of around $285 \mathrm{~nm}$. The ${ }^{1} \mathrm{H}-\mathrm{NMR}$ data of compounds $\mathbf{1}$ and $\mathbf{2}$ (Table 2) were similar to the data published for papyramine and 6-epi-papyramine [27] (Figure 2). The spectrum showed two singlets at $\delta 5.35$ and 6.12 due to the benzylic H-6 proton for epimers 1 and 2, respectively. Two double doublets of the olefinic protons at $\delta 5.98$ and 6.02 were assignable to the $\mathrm{H}-2$ protons of both epimers (compounds 1 and 2, respectively) due to their coupling with the $\mathrm{H}-1$ doublets at 6.59 and $6.51 \mathrm{ppm}$, respectively. The value of the $\mathrm{H}-2 / \mathrm{H}-3$ coupling constant $(J=5.3$ and $5.1 \mathrm{~Hz}$, respectively) was in agreement with a $\beta$-orientation of the hydroxyl group at C-3. The assignment of the aromatic protons was made on the basis of the relative intensities of the signals of both epimers and the benzylic coupling between H-6 and H-7, observed in the 2D COSY experiment. Two signals for the methoxy groups at $\delta 3.90$ and 3.87 were observed, both of them integrating 4.3 protons (since epimers 1 and 2 were in a ratio of 3:1). The protons $\mathrm{H}-4 \mathrm{a}$ and $\mathrm{H}-4 \mathrm{ax}$ showed a large coupling $(J=13.6$ and $13.8 \mathrm{~Hz}$, compound 1 and 2, respectively), due to their trans diaxial configuration. The NOESY contour between H-6 $\alpha$ and $\mathrm{H}-12$ endo allowed us to assign the $\beta$-orientation of the hydroxyl group in compound 1 (Figure 3 ). The coupling between $\mathrm{H}-12 \mathrm{exo}$ and $\mathrm{H}-4 \alpha$ allowed us to establish the conformational orientation of these protons in compound 2 (Figure 3). All the signals were confirmed by 2D-NMR.

Table 2. NMR data for compounds 1 and $2\left(500 \mathrm{MHz}\right.$ for ${ }^{1} \mathrm{H}$ and $125 \mathrm{~Hz}$ for $\left.{ }^{13} \mathrm{C}, \mathrm{CDCl}_{3}\right)$.

\begin{tabular}{|c|c|c|c|c|}
\hline \multirow[b]{2}{*}{ No. } & \multicolumn{2}{|c|}{1} & \multicolumn{2}{|c|}{2} \\
\hline & $\delta_{\mathrm{C}}$, type & $\delta_{\mathrm{H}}(J$ in $\mathrm{Hz})$ & $\delta_{\mathrm{C}}$, type & $\delta_{\mathbf{H}}(J$ in $\mathrm{Hz})$ \\
\hline 1 & $130.7, d$ & $6.59, d(10.0)$ & $129.2, d$ & $6.51, d(10.1)$ \\
\hline 2 & $127.9, d$ & $5.98, d d(5.3$ and 10.4$)$ & $128.4, d$ & $6.02, d d(5.1$ and 10.0$)$ \\
\hline 3 & $63.2, d$ & $4.32, m$ & $62.1, d$ & $4.37, m$ \\
\hline $4 \alpha$ & $31.0, t$ & $1.72, d t(4.0$ and 13.7$)$ & $30.5, t$ & $1.85, d t(4.0$ and 13.4$)$ \\
\hline $4 \beta$ & $31.0, t$ & $2.14, d d(4.1$ and 13.3$)$ & $30.5, t$ & $2.29, d d(4.2$ and 13.8$)$ \\
\hline $4 \mathrm{a}$ & $56.4, d$ & $4.15, d d(4.1$ and 13.6$)$ & $61.7, d$ & $3.89, m$ \\
\hline $6 a$ & $125.2, s$ & - & $123.4, s$ & - \\
\hline 6 & $88.8, d$ & $5.35, s$ & $86.6, d$ & $6.12, s$ \\
\hline 7 & $111.8, d$ & $6.89, s$ & $110.7, d$ & $7.03, s$ \\
\hline 8 & $148.0, s$ & - & $148.4, s$ & - \\
\hline 9 & $148.9, s$ & - & $149.2, \mathrm{~s}$ & - \\
\hline 10 & $105.3, d$ & $6.83, s$ & $105.1, d$ & $6.78, s$ \\
\hline $10 \mathrm{a}$ & $136.0, s$ & - & $133.7, s$ & - \\
\hline $10 \mathrm{~b}$ & $44.2, s$ & - & $44.8, s$ & - \\
\hline $11 \mathrm{exo}$ & $39.9, t$ & $2.03, m$ & $39.8, t$ & 2.03 \\
\hline 11endo & $39.9, t$ & $2.03, m$ & $39.8, t$ & 2.03 \\
\hline $12 \mathrm{exo}$ & $47.4, t$ & 3.37, $d d d(3.8 ; 10.0$ and 13.6) & $41.2, t$ & $3.19, d d d(3.5 ; 10.4$ and 13.6$)$ \\
\hline 12endo & $47.4, t$ & $2.87, d d d(6.5 ; 9.0$ and 13.1$)$ & $41.2, t$ & $3.94, m$ \\
\hline $\mathrm{OMe}$ & $56.1, q$ & $3.90, s$ & $56.1, q$ & $3.90, s$ \\
\hline $\mathrm{OMe}$ & $55.9, q$ & $3.87, s$ & $55.9, q$ & $3.87, s$ \\
\hline
\end{tabular}


<smiles>[R]C1([R])c2cc(OC)c(OC)cc2C23C=CC(OC)CC2N1CC3</smiles>

$\mathrm{R} 1=\mathrm{H}, \mathrm{R} 2=\mathrm{OH} ;$ papyramine $\mathrm{R} 1=\mathrm{OH}, \mathrm{R} 2=\mathrm{H}$; 6-epi-papyramine<smiles>CC(=O)O[C@H]1CC=C2CCN3Cc4cc5c(cc4C2C13)OCO5</smiles><smiles>COc1cc2c(cc1O)CN1CCC3=C[C@H](O)[C@H](OC(C)=O)[C@H]3C21</smiles>

sternbergine

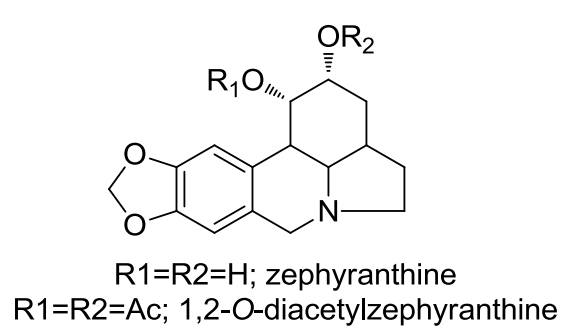

Figure 2. Alkaloids allowing the structural elucidation of compounds 1-4.

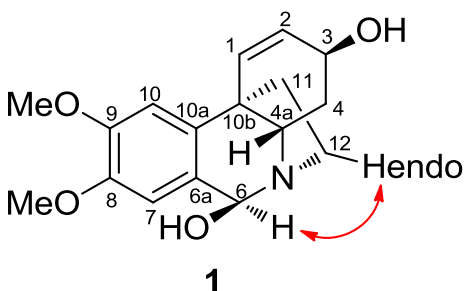

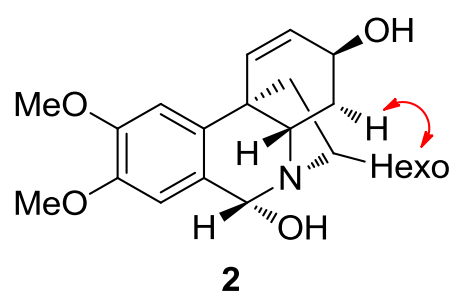

Figure 3. Key NOESY correlations of compounds $\mathbf{1}$ and 2.

\subsubsection{Reticulinine (3) and Isoreticulinine (4)}

Compounds 3 and 4 were obtained from an acetate bulb fraction and isolated as a mixture due to limited sample availability. The HRMS data of compounds 3 and 4 suggested the molecular formula $\mathrm{C}_{17} \mathrm{H}_{22} \mathrm{NO}_{4}$ for the parent ion $[\mathrm{M}+\mathrm{H}]^{+}$at $m / z 334.1651$ (calcd 334.1649). The ${ }^{1} \mathrm{H}-\mathrm{NMR}$ data summarized in Table 3 were similar to those reported for zephyranthine, 1,2-O-diacetylzephyranthine [28] and sternbergine [29] and 1-O-acetylcaranine [30] (Figure 2). A correlation between the protons of the methoxy group and H-10 in the 2D NOESY spectrum allowed us to assign this group at C-9 in both compounds (Figure 4). The two double doublets at $\delta 3.11(J=5.9$ and $10.4 \mathrm{~Hz})$ and $3.22(J=5.9$ and $10.7 \mathrm{~Hz}$ ) were attributed to the $\mathrm{H}-4 \mathrm{a}$ position in compounds 3 and 4 , respectively. The large coupling constant supported a trans-fusion of the B/C rings in both structures. The location and axial configuration of the radical group at C-1 in compounds 3 and 4 , respectively, were deduced from COSY and NOESY experiments (Figure 4). In compound 3, the low magnetic field location of the $\mathrm{H}-1$ and $\mathrm{H}-2$ protons ( $\delta 6.01$ and $4.15 \mathrm{ppm}$, respectively) in the ${ }^{1} \mathrm{H}$ spectrum allowed us to determine the presence of an acetyl group at C-1 and a hydroxyl group at C-2, respectively. Conversely, in compound 4, the low magnetic field of the $\mathrm{H}-1$ and $\mathrm{H}-2$ protons ( $\delta 4.77$ and $5.12 \mathrm{ppm}$, respectively) indicated a hydroxyl group at C-1 and an acetyl group at C-2, respectively. In these compounds, the equatorial $\mathrm{H}-1$ resonated as a triplet at $\delta 6.01(\mathrm{~J}=3.9 \mathrm{~Hz})$ and $4.77(\mathrm{~J}=1.5 \mathrm{~Hz})$, respectively, and was coupled to $\mathrm{H}-10 \mathrm{~b}$ and $\mathrm{H}-2$ in the COSY spectrum, and to H-10 in the NOESY experiment (Figure 4). These data and the large constant coupling between $\mathrm{H}-2$ and $\mathrm{H}-3 \alpha$ in compounds 3 and $4(J=9.8$ and $11.6 \mathrm{~Hz}$, respectively) allowed us to assign the equatorial configuration of the substituent at C-2. From the HMBC spectrum, three bond correlations were observed for $\mathrm{H}-7$ to $\mathrm{C}-9, \mathrm{H}-10$ to $\mathrm{C}-8, \mathrm{H}-7$ to $\mathrm{C}-10 \mathrm{a}$ and $\mathrm{H}-10$ to C-6a, enabling us to identify the resonances of the quaternary carbons C-8, C-9, C-6a and C-10a. In addition, a three-bond coupling between the methoxy protons and C-9 confirmed the NOESY result (Figure 4). 

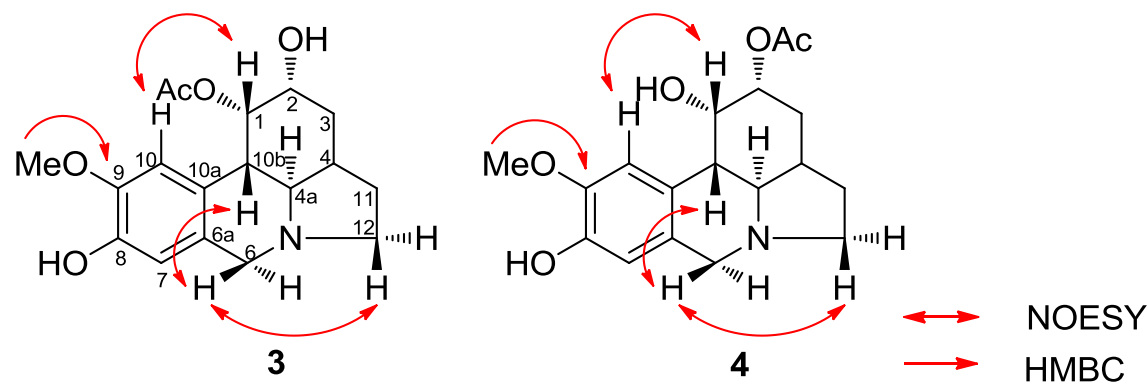

Figure 4. Key NOESY correlations of compounds 3 and 4.

Table 3. NMR data for compounds 3 and $4\left(400 \mathrm{MHz}\right.$ for ${ }^{1} \mathrm{H}$ and $100 \mathrm{~Hz}$ for $\left.{ }^{13} \mathrm{C}, \mathrm{CDCl}_{3}\right)$.

\begin{tabular}{lllll}
\hline & & & & 4 \\
No. & $\delta_{\mathbf{C}}$, type & $\delta_{\mathbf{H}}(\boldsymbol{J}$ in Hz) & $\delta_{\mathbf{C}}$, type & $\delta_{\mathbf{H}}(\boldsymbol{J}$ in $\mathbf{H z})$ \\
\hline 1 & $70.6 d$ & $6.01, t(3.9)$ & $66.9 d$ & $4.77, t(1.5)$ \\
2 & $68.4 d$ & $4.15, d d d(2.8 ; 7.1$ and 9.8$)$ & $72.1 d$ & $5.12, d d d(2.5 ; 5.4$ and 11.6) \\
$3 \alpha$ & $25.8 t$ & $2.02, m$ & $26.8 t$ & $2.23, d d d(6.2 ; 11.8$ and 13.4) \\
$3 \beta$ & $25.8 t$ & $2.02, m$ & $26.8 t$ & $1.95, m$ \\
4 & $36.7 d$ & $2.68, m$ & $36.4 d$ & $2.68, m$ \\
$4 \mathrm{a}$ & $58.0 d$ & $3.11, d d(5.9$ and 10.4$)$ & $57.4 d$ & $3.22, d d(5.9$ and 10.7$)$ \\
$6 \alpha$ & $51.4 t$ & $4.28, d(16.7)$ & $51.6 t$ & $4.29, d(16.4)$ \\
$6 \beta$ & $51.4 t$ & $3.73, d(16.7)$ & $51.6 t$ & $3.74, d(16.9)$ \\
$6 \mathrm{a}$ & $127.7 s$ & - & $127.7 s$ & - \\
7 & $112.7 d$ & $6.67, s$ & $112.9 d$ & $6.68, s$ \\
8 & $144.0 s$ & - & $144.0 s$ & - \\
9 & $145.4 s$ & - & $145.4 s$ & - \\
10 & $106.4 d$ & $6.73, s$ & $106.4 d$ & $6.82, s$ \\
$10 \mathrm{a}$ & $126.7 s$ & - & $126.7 s$ & - \\
$10 \mathrm{~b}$ & $33.1 d$ & $2.68, m$ & $34.3 d$ & $2.59, d(10.5)$ \\
$11 \alpha$ & $29.7 t$ & $1.85, m$ & $29.9 t$ & $2.04, m$ \\
$11 \beta$ & $29.7 t$ & $1.77, m$ & $29.9 t$ & $1.85, m$ \\
$12 \alpha$ & $52.7 t$ & $3.39, m$ & $52.9 t$ & $3.39, m$ \\
$12 \beta$ & $52.7 t$ & $2.81, m$ & $52.9 t$ & $2.81, m$ \\
OMe & $56.0 q$ & $3.82, s$ & $56.1 q$ & $3.89, s$ \\
MeCOO & $172.2 q$ & $2.06, s$ & $170.4 q$ & $2.16, s$ \\
MeCOO & $21.1 q$ & $2.06, s$ & $21.3 q$ & $2.16, s$ \\
\hline
\end{tabular}

\subsection{Biological Activity}

\subsubsection{Antiprotozoal Activity}

6 $\beta$-Hydroxymaritidine (1) and 6 $\alpha$-hydroxymaritidine (2) were isolated as an epimer mixture, which showed low activity against all protozoan parasites tested (Table 4). However, this sample also presented low cytotoxicity $\left(>100 \mu \mathrm{g} \mathrm{mL} \mathrm{m}^{-1}\right)$, so it could be interesting to isolate the epimers and analyze their individual antiprotozoal activity. The quantity of reticulinine (3) and isoreticulinine (4) was insufficient for an antiprotozoal study.

\subsubsection{Acetylcholinesterase and Butyrylcholinesterase Inhibitory Activities}

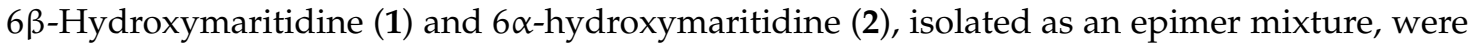
tested for in vitro AChE- and BuChE-inhibitory activities. With galanthamine as a positive control, the epimers exhibited weak AChE inhibition ( $\mathrm{IC}_{50} 90.43 \pm 4.26 \mu \mathrm{M}$ ) and no BuChE inhibition $\left(\mathrm{IC}_{50}>600 \mu \mathrm{M}\right)$, while galanthamine presented $\mathrm{AChE}$ and $\mathrm{BuChE}$ inhibition $\left(\mathrm{IC}_{50} 1.56 \pm 0.14\right.$ and $12.96 \pm 0.65 \mu \mathrm{M}$, respectively). As described below in the molecular docking results, it would be of 
interest to check the cholinesterase inhibitory activities of reticulinine (3) and isoreticulinine (4), but their low amounts precluded these assays.

Table 4. In vitro antiprotozoal and cytotoxic activities of $\mathbf{1}$ and $\mathbf{2}$. Values expressed in $\mu \mathrm{g} \mathrm{m} \mathbf{~}^{-1}$.

\begin{tabular}{|c|c|c|c|c|c|}
\hline Parasite & T. b. rhodesiense & T. cruzi & L. donovani & P. falciparum & Cytotoxicity \\
\hline Stage & Trypomastigotes & Amastigotes & Amastigotes & IEF (intraerythrocytic) & \\
\hline Strain & $\begin{array}{l}\text { STIB } 900 \\
\left(\mathrm{IC}_{50}\right)\end{array}$ & $\begin{array}{l}\text { Tulahuen C4 } \\
\left(\mathrm{IC}_{50}\right)\end{array}$ & $\begin{array}{c}\text { MHOM-ET-67/L82 } \\
\left(\mathrm{IC}_{50}\right)\end{array}$ & $\begin{array}{l}\text { NF54 } \\
\left(\mathrm{IC}_{50}\right)\end{array}$ & $\begin{array}{c}\mathrm{L} 6 \\
\left(\mathrm{IC}_{50}\right)\end{array}$ \\
\hline $\begin{array}{c}\text { melarsoprol } \\
\text { benznidazole } \\
\text { miltefosine } \\
\text { chloroquine }\end{array}$ & 0.0010 & 1.080 & 0.091 & 0.002 & \\
\hline $\begin{array}{l}\text { podophyllotoxin } \\
\text { compounds } 1 \text { and } 2\end{array}$ & 30.68 & 66.11 & $>100$ & 32.86 & $\begin{array}{l}0.007 \\
>100\end{array}$ \\
\hline
\end{tabular}

\subsection{Molecular Docking}

All the new structures obtained from $H$. reticulatum had their theoretical acetyl- and butyrylcholinesterase inhibitory potential evaluated by molecular docking. The results of their binding interactions and orientation patterns with the active site gorge of $\mathrm{AChE}$ and $\mathrm{BuChE}$ are represented in Table 5 .

Table 5. Estimated energies of reaction and inhibition constants for the new compounds in the active sites of AChE and BuChE.

\begin{tabular}{|c|c|c|c|}
\hline Alkaloids & 1DX6 $^{\text {a }}\left(\mathrm{kcal} \mathrm{mol}^{-1}\right)$ & $4 \mathrm{EY7}^{\mathrm{b}}\left(\mathrm{kcal} \mathrm{mol}^{-1}\right)$ & $4 \mathrm{BDS}^{\mathrm{c}}\left(\mathrm{kcal} \mathrm{mol}^{-1}\right)$ \\
\hline $6 \beta$-hydroxymaritidine (1) & -8.49 & -9.44 & -8.95 \\
\hline $6 \alpha$-hydroxymaritidine (2) & -8.25 & -8.75 & -8.72 \\
\hline reticulinine (3) & -8.88 & -8.87 & -8.10 \\
\hline isoreticulinine (4) & -9.02 & -9.80 & -8.12 \\
\hline galanthamine (11) & -9.36 & -10.10 & -8.74 \\
\hline
\end{tabular}

a 1DX6: Torpedo californica Acetylcholinesterase; b 4EY7: Human Acetylcholinesterase; c 4BDS: Human
Butyrylcholinesterase.

The simulated molecular docking on the 1DX6 and 4EY7 structures showed that the alkaloid isoreticulinine (4) theoretically has a higher inhibitory effect against AChE than reticulinine (3), $6 \beta$-hydroxymaritidine (1) and $6 \alpha$-hydroxymaritidine (2), but lower than galanthamine by 0.34 and $0.30 \mathrm{kcal} \mathrm{mol}^{-1}$, respectively. The docking results obtained for isoreticulinine suggest that the presence of a hydroxyl and an acetyl group at the C-1 and C-2 positions, respectively, theoretically improves the AChE inhibition on the 1DX6 and 4EY7 structures in comparison with reticulinine. Structural representations of the best conformation of the complexed active site of the TcAChE with galanthamine and isoreticulinine (4) are depicted in Figure 5.

The molecular docking results reported in Table 5 are analyzed here in terms of different interactions between the alkaloids and active site of the TcAChE protein: hydrogen bonds, $\pi-\pi$ stacking and anionic interactions. Regarding hydrogen bonding, galanthamine showed the highest stability due to two strong interactions with the Glu199 and Ser200 residues, while the isoreticulinine complex presented only one interaction with the Ser200 residue. Both these alkaloids have a similar localization according to $\pi-\pi$ stacking, interactions with Trp84, Phe330 and Asp72 residues, and anionic stabilization. The hydrogen bond interaction of reticulinine (3) is as depicted in Figure 5 for isoreticulinine (4), with a distance close to $1.9 \mathrm{~A}$. The hydrogen bond interactions for $6 \beta$-hydroxymaritidine (1) and $6 \alpha$-hydroxymaritidine (2) are similar, although anionic and $\pi-\pi$ stacking interactions suggest a different, more distant localization, in accordance with the binding free energies reported in Table 5. 
(a) Galanthamine in $\mathrm{TcAChE}$

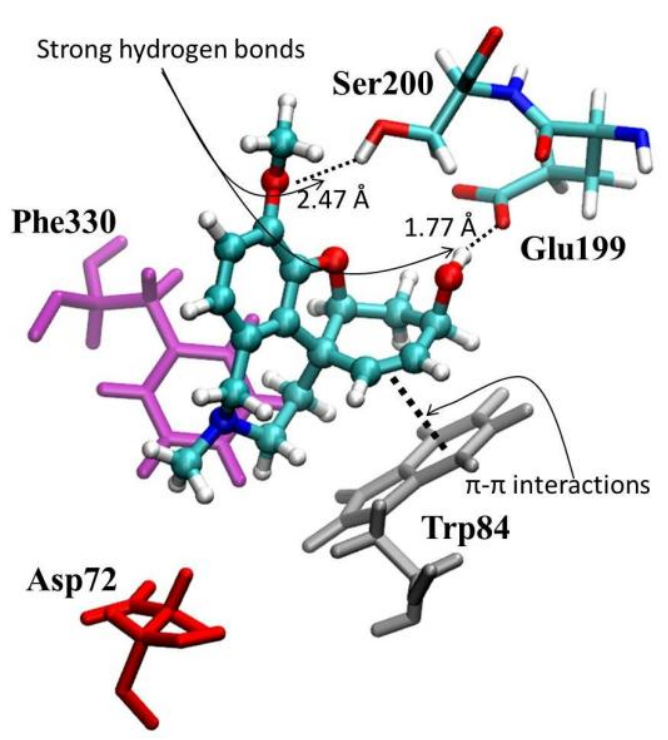

(b) Isoreticulinine in $\mathrm{TcAChE}$

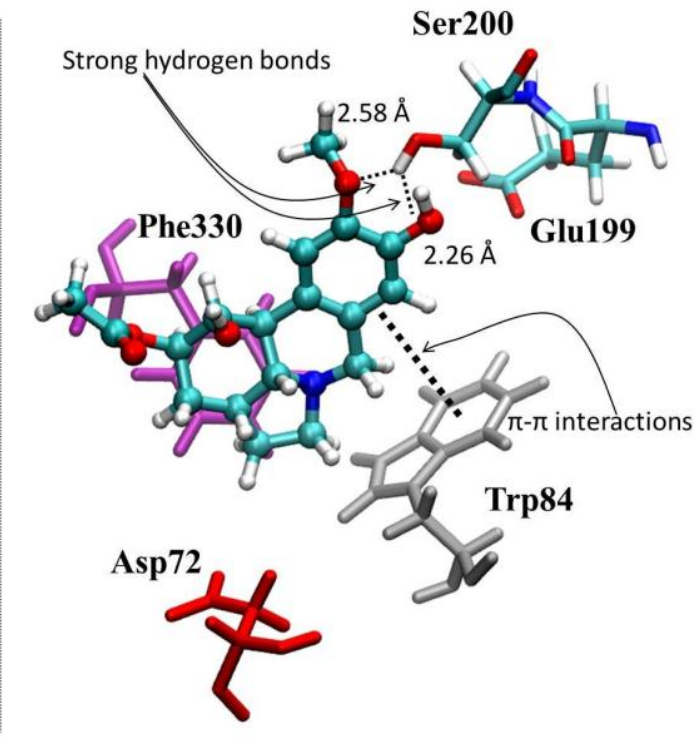

Figure 5. Graphical representations of (a) galanthamine-TcAChE and (b) isoreticulinine-TcAChE complexes.

The molecular simulation of $6 \beta$-hydroxymaritidine (1) on the 4BDS structure theoretically showed more potent enzymatic inhibition against BuChE than $6 \alpha$-hydroxymaritidine (2), isoreticulinine (4) and reticulinine (3), and interestingly, it was higher than galanthamine by $0.21 \mathrm{kcal} \mathrm{mol}^{-1}$. These results also indicate that $6 \alpha$-hydroxymaritidine (2) theoretically has virtually the same inhibitory activity as galanthamine toward BuChE, differing by only $0.02 \mathrm{kcal} \mathrm{mol}^{-1}$. Furthermore, the docking results propose that the $\beta$-orientation of the hydroxyl group at the C-6 position in $6 \beta$-hydroxymaritidine (1) could improve the butyrylcholinesterase inhibition on the 4BDS structure by $0.23 \mathrm{kcal} \mathrm{mol}^{-1}$ compared to the $\alpha$-orientation of the hydroxyl group at the C-6 position in $6 \alpha$-hydroxymaritidine (2). Structural representations of the best conformation of the complexed active site of human BuChE with 6ß-hydroxymaritidine (1) are presented in Figure 6.

(a) 6ß-hydroxymaritidine in $\mathrm{hBChE}$

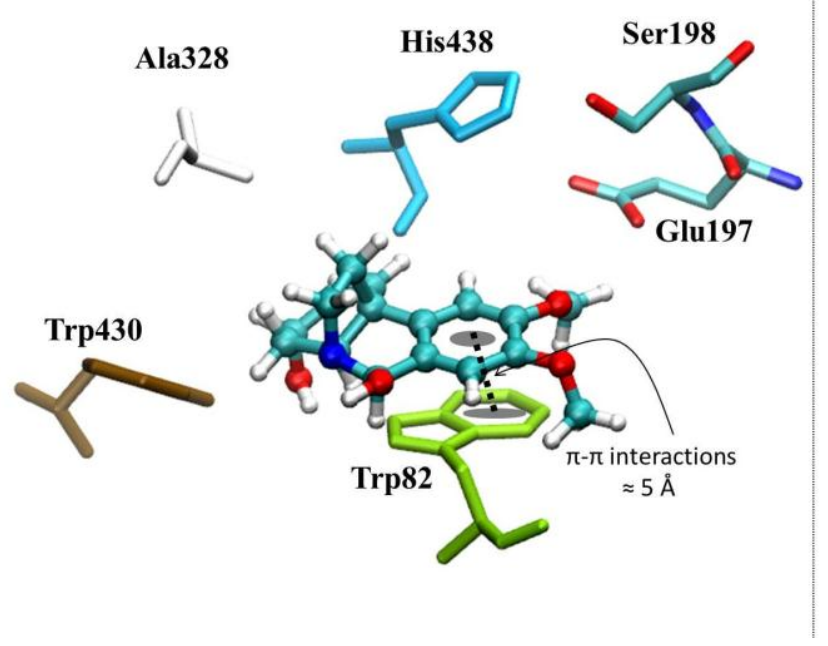

(b) Isoreticulinine in $\mathrm{hBChE} \quad$ hydrogen bond

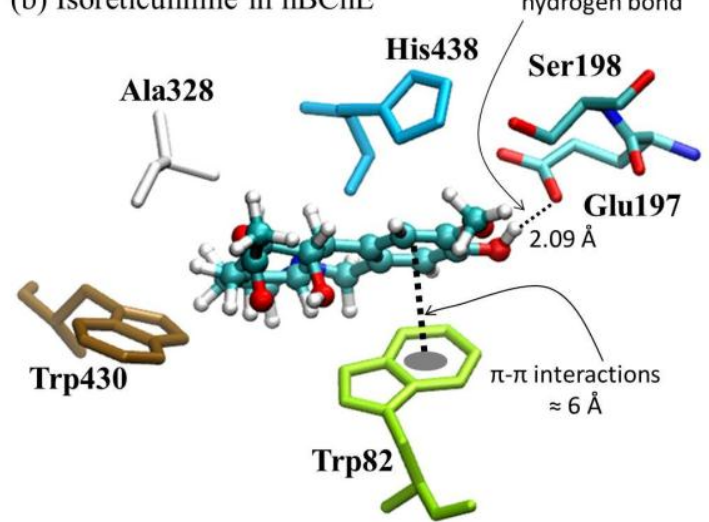

Figure 6. Graphical representations of (a) $6 \beta$-hydroxymaritidine- $h \mathrm{BChE}$ and (b) isoreticulinine $h \mathrm{BChE}$ complexes. 
In the case of BuChE, 4BDS in the PDB code, the crystallographic data show that tacrine, a molecule for anti-Alzheimer's drugs targeting acetyl- and butyryl-cholinesterase, is stabilized by $\pi-\pi$ stacking interactions between the aromatic rings and the Trp82 residue; additionally, this ligand is stabilized by the presence of hydrophobic interactions with Trp430, Ala328 and His438. On the other hand, similar to TcAChE, the active site shows the presence of two available residues available for hydrogen bond interactions, Glu197 and Ser198. In terms of $\pi-\pi$ stacking interactions, Figure 6 shows that $6 \beta$-hydroxymaritidine (1) is more stable than isoreticulinine (4). However, the localization of $6 \beta$-hydroxymaritidine in the active site is not appropriate for forming hydrogen bonds with the Glu197 and Ser198 residues. The results suggest that in an ideal BuChE inhibitor $\pi-\pi$ stacking and hydrogen bond interactions should be in equilibrium, and among the tested molecules isoreticulinine was closest to this definition. In terms of hydrophobic interactions, all molecular docking analyses reported similar interactions between the alkaloids and Trp430, Ala328 and His438 residues.

The theoretical results obtained by molecular docking for $6 \beta$-hydroxymaritidine (1) and $6 \alpha$-hydroxymaritidine (2) BuChE inhibition are not in agreement with the experimental assays. The difference between the BuChE structure used for the molecular docking (human) and experiments (equine serum), as well as the inability of these compounds to arrive to the active site gorge of $\mathrm{BuChE}$ may help understand the difference between the theoretical and practical results. Moreover, the use of an epimer mixture in the assays could also have contributed to the discrepancy between the theoretical and practical results.

According to the molecular interactions shown in the docking analysis, the isoreticulinine alkaloid (4) may be catalogued as a potential inhibitory molecule based on its very good interaction with the active site through strong hydrogen bonds in both of the proteins evaluated, AChE and BuChE. Additionally, the position of isoreticulinine alkaloid (4) on the gorge of the active sites showed that it can be stabilized by $\pi-\pi$ stacking and hydrophobic interactions.

$\mathrm{AChE}$ is highly selective for ACh hydrolysis, while $\mathrm{BuChE}$ is able to metabolize different substrates [31]. AChE activity in the brain of Alzheimer's disease patients tends to decrease, while that of BuChE increases [32]. Consequently, the search for a structure able to simultaneously inhibit both enzymes may provide a better therapeutic response for Alzheimer's disease than AChE-selective agents [33]. This information adds to the importance of the results obtained herein for isoreticulinine (4) by molecular docking.

\section{Materials and Methods}

\subsection{General Experimental Procedures}

About $2 \mathrm{mg}$ of each alkaloid extract were dissolved in $1000 \mu \mathrm{L}$ of $\mathrm{MeOH}$ and / or $\mathrm{CHCl}_{3}$ and injected directly into the GC-MS apparatus (Agilent Technologies 6890N coupled with MSD5975 inert XL, Santa Clara, CA, USA) operating in the EI mode at $70 \mathrm{eV}$. A Sapiens-X5 MS column $(30 \mathrm{~m} \times 0.25 \mathrm{~mm}$ i.d., film thickness $0.25 \mu \mathrm{m}$, Teknokroma, Barcelona, Spain) was used. The temperature gradient performed was the following: $2 \mathrm{~min}$ at $100{ }^{\circ} \mathrm{C}, 100-180^{\circ} \mathrm{C}$ at $15^{\circ} \mathrm{C} \mathrm{min}^{-1}, 180-300{ }^{\circ} \mathrm{C}$ at $5^{\circ} \mathrm{C} \mathrm{min}^{-1}$ and $10 \mathrm{~min}$ hold at $300{ }^{\circ} \mathrm{C}$. The injector and detector temperatures were $250^{\circ} \mathrm{C}$ and $280^{\circ} \mathrm{C}$, respectively, and the flow-rate of carrier gas (He) was $1 \mathrm{~mL} \mathrm{~min}^{-1}$. A split ratio of 1:10 was applied and the injection volume was $1 \mu \mathrm{L}$.

${ }^{1} \mathrm{H},{ }^{13} \mathrm{C}-\mathrm{NMR}$, COSY, NOESY, HSQC, and HMBC spectra were recorded on a Varian VNMRS $500 \mathrm{MHz}$ (Palo Alto, CA, USA) and a Bruker $400 \mathrm{MHz}$ Avance III (Billerica, MA, USA) equipped with CryoProbe Prodigy, using $\mathrm{CDCl}_{3}$ as the solvent and TMS as the internal standard. Chemical shifts are reported in units of $\delta(\mathrm{ppm})$ and coupling constants $(J)$ expressed in Hz. CD, UV and IR spectra were recorded on Jasco-J-810 (Easton, MD, USA), Dinko UV2310 (Barcelona, Spain) and Thermo Scientific Nicolet iN10 MX spectrophotometers (Waltham, MA, USA), respectively. HR-ESI-MS spectra were obtained on an LC/MSD-TOF (2006) mass spectrometer (Agilent technologies, Santa Clara, CA, USA). Silica gel SDS chromagel 60 A CC (6-35 $\mu \mathrm{m})$ (Carlo Erba Reagents, Val de Reuil, France) was used for VLC, and silica gel 60 F254 (Merck, Darmstadt, Germany) for analytics and preparative TLC. Spots 
on chromatograms were detected under UV light (254 nm) (Spectroline, Westbury, NY, USA) and by Dragendorff's reagent stain.

\subsection{Plant Material}

Bulbs and leaves of Hippeastrum reticulatum Herb. were collected in Floresta Nacional de Goytacazes (Espírito Santo, Brazil) in May 2015. The samples were authenticated by Dr Julie H. A. Dutilh, Universidade de Campinas (UNICAMP, Campinas, Brazil). A specimen voucher (VIES 38724) has been deposited in the Herbarium VIES from Universidade Federal do Espírito Santo (UFES, Vitória, Brazil).

\subsection{Extraction and Isolation}

Fresh bulbs $(1.5 \mathrm{~kg}$ ) and leaves (400 g) of $H$. reticulatum were collected and macerated with $\mathrm{MeOH}$ $(2 \times 1.0 \mathrm{~L})$ at room temperature for 4 days, the combined macerate filtered and the solvent evaporated to dryness under reduced pressure. The bulb and leaf crude extracts (117.3 and $53.5 \mathrm{~g}$, respectively) were then acidified to $\mathrm{pH} 3$ with diluted $\mathrm{H}_{2} \mathrm{SO}_{4}(2 \%, v / v)$. The neutral material was removed with $\mathrm{Et}_{2} \mathrm{O}(10 \times 150 \mathrm{~mL})$ and then extracted with EtOAc $(3 \times 150 \mathrm{~mL})$ to provide the acid EtOAc extracts (0.60 and $0.44 \mathrm{~g}$, respectively). The aqueous solutions were basified up to $\mathrm{pH} 9-10$ with $\mathrm{NH}_{4} \mathrm{OH}(25 \%$, $v / v)$ and extracted with $n$-Hex $(16 \times 150 \mathrm{~mL})$ to give the $n$-Hex extracts $(0.14$ and $0.02 \mathrm{~g}$, respectively), which were followed by extraction with EtOAc $(15 \times 150 \mathrm{~mL})$ to provide the EtOAc extracts $(1.6$ and $0.3 \mathrm{~g}$, respectively) and finally extracted with EtOAc:MeOH $(3: 1, v / v)(4 \times 150 \mathrm{~mL})$ to provide the EtOAc:MeOH extracts (2.10 and $1.56 \mathrm{~g}$, respectively).

The extracts were subjected to a combination of chromatographic techniques, including vacuum liquid chromatography (VLC) [34] and semi-preparative TLC. The general VLC procedure consisted of the use of a silica gel $60 \mathrm{~A}(6-35 \mu \mathrm{m})$ column with a height of $4 \mathrm{~cm}$ and a variable diameter according to the amount of sample ( $2.5 \mathrm{~cm}$ for $400-1000 \mathrm{mg} ; 1.5 \mathrm{~cm}$ for $150-400 \mathrm{mg}$ ). Alkaloids were eluted with $n$-Hex containing increasing EtOAc concentrations, followed by neat EtOAc, which was gradually enriched with $\mathrm{MeOH}$ (reaching a maximum concentration of 20\%, v/v). Fractions of 10-15 mL were collected, monitored by TLC (UV $254 \mathrm{~nm}$, Dragendorff's reagent [35,36]), and combined according to their profiles. For semi-preparative TLC, silica gel $60 \mathrm{~F}_{254}$ was used $(20 \mathrm{~cm} \times 20 \mathrm{~cm} \times 0.25 \mathrm{~mm})$ together with different solvent mixtures depending on each particular sample (EtOAc:MeOH, 9:1, v/v or EtOAc:MeOH, 8:2, v/v), always in an environment saturated with ammonia. Each known alkaloid was identified by GC-MS and the four new alkaloids were structurally elucidated by NMR.

The EtOAc leaf extract $(0.3 \mathrm{~g})$ was subjected to a VLC column $(2.5 \mathrm{~cm} \times 4.0 \mathrm{~cm})$, starting the elution with $100 \% n$-Hex, gradually increasing the polarity with EtOAc up to $100 \%$ EtOAc, and finally increasing the $\mathrm{MeOH}$ percentage in the mixture up to a ratio of EtOAc:MeOH $(80: 20, v / v)$, similar to the methodology used in Hippeastrum aulicum by Bessa and co-workers [37]. 580 fractions (10 mL each) were collected, analyzed by TLC and grouped in nine fractions. Fraction 5 (72.8 mg), eluted with EtOAc:MeOH (eluted with 95:05 until 90:10, v/v), was subjected to a semi-preparative TLC using 2 plates and a mobile phase consisting of EtOAc:MeOH (80:20, v/v) in an environment saturated with ammonia, and $15.60 \mathrm{mg}$ of the epimer mixture $\mathbf{1}$ and $\mathbf{2}$ was isolated.

Exclusion chromatography was carried out using a Sephadex LH-20 column $(2.5 \mathrm{~cm} \times 40 \mathrm{~cm})$ to clean and separate the alkaloids present in the EtOAc bulb extract (1.6 g). It was eluted with $100 \%$ $\mathrm{MeOH}$, producing 147 fractions, each one containing about $2 \mathrm{~mL}$, which were monitored by TLC and grouped in four fractions. Fraction $2(801 \mathrm{mg})$ was chromatographed again in a Sephadex LH-20 in the same conditions, producing 120 sub-fractions, which were grouped in seven sub-fractions. Sub-fraction 2 (10.2 mg) was subjected to a TLC plate, applying 3 runs over a mobile phase consisting of EtOAc:MeOH $(80: 20, v / v)$ in an environment saturated with ammonia to obtain $1.09 \mathrm{mg}$ of the isomers 3 and 4 . 


\subsection{Characterization of Compounds}

$6 \beta$-Hydroxymaritidine (1) and $6 \alpha$-hydroxymaritidine (2): Amorphous solid; $[\alpha]_{\mathrm{D}}^{22}-11.22\left(c 0.98, \mathrm{CHCl}_{3}\right)$; $\mathrm{UV}(\mathrm{MeOH}) \lambda_{\max }(\log \varepsilon): 282.5$ (3.64), 234.0 (3.92) nm; CD (MeOH, $\left.20{ }^{\circ} \mathrm{C}\right) \Delta \varepsilon_{250}-340, \Delta \varepsilon_{284}+5938$; IR $v_{\max } \mathrm{cm}^{-1} 3341,2958,1609,1512,1464,1406,1268,1246,1222,1192,1141,1113,1043,1017,941,866$, 779,$746 ;{ }^{1} \mathrm{H}-\mathrm{NMR}\left(\mathrm{CDCl}_{3}, 500 \mathrm{MHz}\right)$ and ${ }^{13} \mathrm{C}-\mathrm{NMR}\left(\mathrm{CDCl}_{3}, 125 \mathrm{MHz}\right)$ see Table 2; EIMS data shown in Table 1 ; HREIMS of $[\mathrm{M}+\mathrm{H}]^{+}$at $m / z 304.1544$ (calcd 304.1543).

Reticulinine (3) and isoreticulinine (4): Amorphous solid; ${ }^{1} \mathrm{H}-\mathrm{NMR}\left(\mathrm{CDCl}_{3}, 400 \mathrm{MHz}\right)$ and ${ }^{13} \mathrm{C}-\mathrm{NMR}$ $\left(\mathrm{CDCl}_{3}, 100 \mathrm{MHz}\right)$ see Table 3; IR $v_{\max } \mathrm{cm}^{-1}$ 2852, 1732, 1571, 1513, 1452, 1375, 1240, 1114, 1047; EIMS data shown in Table $1 ;[\mathrm{M}+\mathrm{H}]^{+}$at $m / z 334.1651$ (calcd 334.1649).

\subsection{Biological Activity}

\subsubsection{Antiprotozoal Activity}

In vitro tests for the biological activity of the epimers $6 \beta$-hydroxymaritidine (1) and 6 $\alpha$-hydroxymaritidine (2) against Trypanosoma brucei rhodesiense (trypomastigotes forms, STIB 900 strain), Trypanosoma cruzi (amastigotes forms, Tulahuen C4 strain), Leishmania donovani (amastigotes forms, MHOM-ET-67/L82 strain), and Plasmodium falciparum (intraerythrocytic forms, IEF, NF54 strain) and a cytotoxicity test against the mammalian L6 cell line from rat skeletal myoblasts were carried out at the Swiss Tropical and Public Health Institute (Swiss TPH, Basel, Switzerland) according to established protocols as described by Orhan and co-workers [38]. The reference drugs used in these assays were melarsoprol, benznidazole, miltefosine, chloroquine and podophyllotoxin, respectively.

\subsubsection{Acetylcholinesterase and Butyrylcholinesterase Inhibitory Activities}

Cholinesterase inhibitory activities were analyzed as by Ellman and co-workers [39] with some modifications as by López and co-workers [40]. Fifty microliters of AChE or BuChE in phosphate buffer $\left(8 \mathrm{mM} \mathrm{K}_{2} \mathrm{HPO}_{4}, 2.3 \mathrm{mM} \mathrm{NaH} \mathrm{PO}_{4}, 0.15 \mathrm{NaCl}, \mathrm{pH} 7.5\right)$ and $50 \mu \mathrm{L}$ of the sample dissolved in the same buffer were added to the wells. The plates were incubated for 30 minutes at room temperature before $100 \mu \mathrm{L}$ of the substrate solution $\left(0.1 \mathrm{M} \mathrm{Na}_{2} \mathrm{HPO}_{4}, 0.5 \mathrm{M} \mathrm{DTNB}\right.$, and $0.6 \mathrm{mM}$ ATCI or $0.24 \mathrm{mM}$ BTCI in Millipore water, $\mathrm{pH}$ 7.5) was added. The absorbance was read in a Labsystem microplate reader (Thermo Electron Corporation, Vantaa, Finland) at $405 \mathrm{~nm}$ after 10 minutes. Enzyme activity was calculated as a percentage compared to an assay using a buffer without any inhibitor. The cholinesterase inhibitory data were analyzed with the software Microsoft Office Excel 2010. The epimer concentrations used to calculate $\mathrm{IC}_{50}$ values were 10, 20, 40, 60, 80, 100 and $200 \mu \mathrm{g} \mathrm{mL} \mathrm{m}^{-1}$ both AChE and BuChE assays.

\subsection{Molecular Docking}

The molecular docking simulations for 6 $\beta$-hydroxymaritidine (1), $6 \alpha$-hydroxymaritidine (2), reticulinine (3) and isoreticulinine (4) were performed to investigate the binding mode in the active site of three different enzymes, Torpedo californica AChE (TcAChE), hBChE, and hAChE, proteins with PDB codes 1DX6 [41], 4BDS [42], and 4EY7 [43], respectively. The 3D structures of the alkaloids were drawn with the Chemcraft program [44] and then submitted to a geometrical optimization procedure using PBE0 [45] /6-311+g* [46] level of theory with the Gaussian 09 program [47]. All optimized alkaloids were confirmed as a minimum on the potential energy surface. The docking simulations for the set of optimized ligands were performed using the AutoDock v.4.2 program [48].

AutoDock combines a rapid energy evaluation through precalculated grids of affinity potentials with a variety of search algorithms to find suitable binding positions for a ligand on a given macromolecule. To compare the results from the docking simulations, the water molecules, cofactors, and ions were excluded from each X-ray crystallographic structure. Likewise, the polar hydrogen atoms of the enzymes were added and the non-polar hydrogen atoms were merged. Finally, the 
enzyme was treated as a rigid body. The grid maps of interaction energy for various atom types with each macromolecule were calculated by the auxiliary program AutoGrid choosing a grid box with dimensions of $60 \times 60 \times 60 \AA$ around the active site, which was sufficiently large to include the most important residues of each enzyme. The docking searches for the best orientations of the ligands binding to the active site of each protein were performed using the Lamarckian Genetic Algorithm, (LGA) [49]. The LGA protocol applied a population size of 2000 individuals, while 2,500,000 energy evaluations were used for the 50 LGA runs. The best conformations were chosen from the lowest docked energy solutions in the cluster populated by the highest number of conformations. The best docking complex solutions (poses) were analyzed according to the potential intermolecular interactions (ligand/enzyme), such as hydrogen bonding and the cation- $\pi, \pi-\pi$ stacking.

\section{Conclusions}

This is the first report about the alkaloid profile and biological activities of H. reticulatum. Twelve alkaloids were identified in this species, eight known and four new, $6 \alpha$-hydroxymaritidine, $6 \beta$-hydroxymaritidine, reticulinine and isoreticulinine. The low cytotoxicity of the epimers 6 $\beta$-hydroxymaritidine (1) and $6 \alpha$-hydroxymaritidine (2) and the very good interactions of isoreticulinine (4) with the active sites of the enzymes $\mathrm{AChE}$ and BuChE by molecular docking suggests that $H$. reticulatum has high potential as a source of alkaloids with pharmacological activities. Finally, as the molecular docking results indicate that isoreticulinine alkaloid (4) is a promising molecule in the treatment of Alzheimer's disease, the synthesis of this compound and its analogues will be undertaken in future work in our laboratories.

Acknowledgments: The authors (Research Group 2014-SGR-920) thank CCiTUB and Programa CYTED (416RT0511) for technical and financial support, respectively. We thank M. Cal, S. Keller-Märki and R. Rocchetti for assistance with parasitic assays. JASZ acknowledges CNPq (Brazil) for a research fellowship. LRT is thankful to CAPES (Coordenação de Pessoal de Nível Superior-Bolsista CAPES, Processo 13553135) for a doctoral fellowship and VDDS is also thankful to CAPES (Processo CSF-PVE-S 88887115334/2015-00) for doctoral fellowship.

Author Contributions: Jaume Bastida designed the experiments, analyzed the data and wrote the paper. Luciana R. Tallini performed the experiments, analyzed the data and wrote the paper. Edison H. Osorio performed the molecular docking experiment and wrote the paper. Vanessa Dias dos Santos and Warley de Souza Borges collected the plant, performed the extraction experiments and wrote the paper. Marcel Kaiser performed the antiprotozoal experiments and wrote the paper. Francesc Viladomat and José Angelo S. Zuanazzi wrote the paper.

Conflicts of Interest: The authors declare no conflict of interest.

\section{References}

1. Lee, M.-L.; Schneider, G. Scaffold architecture and pharmacophoric properties of natural products and trade drugs: application in the design of natural product- based combinatorial libraries. J. Comb. Chem. 2001, 3, 284-289. [CrossRef] [PubMed]

2. Harvey, A. Strategies for discovering drugs from previously unexplored natural products. Drug Discov. Today 2000, 5, 294-300. [CrossRef]

3. Rodrigues, T.; Reker, D.; Schneider, P.; Schneider, G. Counting on natural products for drug design. Nat. Chem. 2016, 8, 531-541. [CrossRef] [PubMed]

4. Stratton, C.F.; Newman, D.J.; Tan, D.S. Cheminformatic comparision of approved drugs from natural product versus synthetic origins. Bioorg. Med. Chem. Lett. 2015, 25, 4802-4807. [CrossRef] [PubMed]

5. Newman, D.J.; Cragg, G.M. Natural products as sources of new drugs from 1981 to 2014. J. Nat. Prod. 2016, 79, 629-661. [CrossRef] [PubMed]

6. APG III. An update of the Angiosperm Phylogeny Group classification for the orders and families of flowering plants: APG III. Bot. J. Linn. Soc. 2009, 161, 105-121. [CrossRef]

7. Chase, M.W.; Reveal, J.L.; Fay, M.F. A subfamilial classification for the expanded asparagalean families Amaryllidaceae, Asparagaceae and Xanthorrhoeaceae. Bot. J. Linn. Soc. 2009, 161, 132-136. [CrossRef]

8. The Plant List. A Working List of All Plant Species. Available online: http://www.theplantlist.org/1.1/ browse/A/Amaryllidaceae/ (accessed on 27 April 2017). 
9. Candido, R.S.; da Silva Fourny, A.C.; Gonçalves-Esteves, V.; Lopes, R.C. Hippeastrum species in areas of resting in the state of Rio de Janeiro, Brazil: pollen characters. Acta Bot. Bras. 2013, 27, 661-668. [CrossRef]

10. Bastida, J.; Lavilla, R.; Viladomat, F. Chemical and biological aspects of Narcissus Alkaloids. In The Alkaloids: Chemistry and Physiology; Cordell, G.A., Ed.; Elsevier: Amsterdam, The Netherlands, 2006; Volume 63, pp. 87-179.

11. Maelicke, A.; Samochocki, M.; Jostock, R.; Fehrenbacher, A.; Ludwig, J.; Albuquerque, E.X.; Zerlin, M. Allosteric sensitization of nicotinic receptors by galantamine, a new treatment strategy for Alzheimer's disease. Biol. Psychiatry 2001, 49, 279-288. [CrossRef]

12. Alzheimer's Disease International. Available online: https://www.alz.co.uk/research/ WorldAlzheimerReport2016.pdf (accessed on 13 October 2017).

13. Querfurth, H.W.; LaFerla, F.M. Alzheimer's disease. N. Engl. J. Med. 2010, 362, 329-344. [CrossRef] [PubMed]

14. Konrath, E.L.; Passos, C.S.; Klein-Júnior, L.C.; Henriques, A.T. Alkaloids as source of potential anticholinesterase inhibitors for the treatment of Alzheimer's disease. J. Pharm. Pharmacol. 2013, 65, 1701-1725. [CrossRef] [PubMed]

15. World Health Organization Neglected Tropical Diseases. Available online: http://www.who.int/neglected diseases/diseases/en/ (accessed on 1 September 2017).

16. Klug, D.M.; Gelb, M.H.; Pollastri, M.P. Repursposing strategies for tropical disease drug discovery. Bioorg. Med. Chem. Lett. 2016, 26, 2569-2576. [CrossRef] [PubMed]

17. Meerow, A.W.; Snijman, D.A. Amaryllidaceae. In The families and genera of vascular plants. Flowering Plants, Monocotyledons Lilianae. (except Orchidaceae.); Kubitzki, K., Ed.; Springer: Berlin, Germany, 1998; Volume 3, pp. 83-110.

18. Dutilh, J.H.A. Amaryllidaceae. In Catálogo de Plantas e Fungos do Brasil; Jakobsson, A., Ed.; Sindicato Nacional de Editores de Livros: Rio de Janeiro, Brazil, 2010; Volume 1, pp. 596-599.

19. Deepa, C.P.; Kuriakose, B.B. Pharmacognostic and phytochemical evaluation of the bulbs of Hippeastrum. puniceum (Lam.) Voss. IJPPR 2014, 6, 399-404.

20. Da Silva, A.F.S.; de Andrade, J.P.; Bevilaqua, L.R.M.; de Souza, M.M.; Izquierdo, I.; Henriques, A.T.; Zuanazzi, J.A.S. Anxiolytic-, antidepressant- and anticonvulsant-like effects of the alkaloid montanine isolated from Hippeastrum. vittatum. Pharmacol. Biochem. Behav. 2006, 85, 148-154. [CrossRef] [PubMed]

21. Giordani, R.B.; Junior, C.O.R.; de Andrade, J.P.; Bastida, J.; Zuanazzi, J.A.S.; Tasca, T.; Almeida, M.V. Lycorine derivatives against Trichomonas vaginalis. Chem. Biol. Drug. Des. 2012, 80, 129-133. [CrossRef] [PubMed]

22. Carvalho, K.R.; Silva, A.B.; Torres, M.C.M.; Pinto, F.C.L.P.; Guimaraes, L.A.; Rocha, D.D.; Silveira, E.R.; Costa-Lotufo, L.V.; Braz-Filho, R.; Pessoa, O.D.L. Cytotoxic Alkaloids from Hippeastrum. solandriflorum Lindl. J. Braz. Chem. Soc. 2015, 26, 1976-1980. [CrossRef]

23. Silva, A.F.S.; de Andrade, J.P.; Machado, K.R.B.; Rocha, A.B.; Apel, M.A.; Sobral, M.E.G.; Henriques, A.T.; Zuanazzi, J.A. Screening for cytotoxic activity of extracts and isolated alkaloids from bulbs of Hippeastrum. vittatum. Phytomedicine 2008, 15, 882-885. [CrossRef] [PubMed]

24. Nitteranon, V.; Kittiwongwattana, C.; Vuttipongchaikij, S.; Sakulkoo, J.; Srijakkoat, M.; Chokratin, P.; Harinasut, P.; Suputtitada, S.; Apisitwanich, S. Evaluations of the mutagenicity of a pigment extract from bulb culture of Hippeastrum. reticulatum. Food Chem. Toxicol. 2014, 69, 237-243. [CrossRef] [PubMed]

25. Clippel, J.K.; Carmo, H.N.C.; Nascimento, L.C.Z.; Cuzzuol, G.R.F. Análise química em órgãos de reserva de algumas herbáceas e arbóreas ocorrentes na flora do Espírito Santo, Brasil. Acta Bot. Bras. 2008, 22, 1057-1067. [CrossRef]

26. Hang, T.T.M.; Phuong, P.T.M.; Dung, T.T.M.; Miyajima, I. Preliminary chromosome studies on Hippeastrum. species from Vietnam. J. Fac. Agric. Kyushu Univ. 2015, 60, 51-55.

27. Bastida, J.; Codina, C.; Francesc, V. Narcissus alkaloids, XIII. Complete assignment of the NMR spectra of papyramine and 6-epi-papyramine by two-dimensional NMR spectroscopy. J. Nat. Prod. 1990, 53, 1456-1462. [CrossRef]

28. Herrera, M.R.; Machocho, A.K.; Nair, J.J.; Campbell, W.E.; Brun, R.; Viladomat, F.; Codina, C.; Bastida, J. Alkaloids from Cyrtanthus. elatus. Fitoterapia 2001, 72, 444-448. [CrossRef]

29. Evidente, A.; Iasiello, I.; Randazzo, G. Isolation of sternbergine, a new alkaloid from bulbs of Sternbergia. lutea. J. Nat. Prod. 1984, 47, 1003-1008. [CrossRef]

30. Tallini, L.R.; Andrade, J.P.; Kaiser, M.; Viladomat, F.; Nair, J.J.; Zuanazzi, J.A.S.; Bastida, J. Alkaloid constituents of the Amaryllidaceae plant Amaryllis belladonna L. Molecules 2017, 22, 1437. [CrossRef] [PubMed] 
31. Greig, N.H.; Lahiri, D.K.; Sambamurti, K. Butyrylcholinesterase: An important new target in Alzheimer's disease therapy. Int. Psychogeriatr. 2002, 14, 77-91. [CrossRef] [PubMed]

32. Giacobini, E. Cholinesterase inhibitors: New roles and therapeutic alternatives. Pharmacol. Res. 2004, 50, 433-440. [CrossRef] [PubMed]

33. Ballard, C.G. Advances in the treatment of Alzheimer's disease: benefits of dual cholinesterase inhibition. Eur. Neurol. 2002, 47, 64-70. [CrossRef] [PubMed]

34. Coll, J.C.; Bowden, B.F. The application of vacuum liquid chromatography to the separation of terpene mixtures. J. Nat. Prod. 1986, 49, 934-936. [CrossRef]

35. Munier, R.; Macheboeuf, M. Paper partion microchromatography of alkaloids and various biological nitrogenous bases. III. Examples of the separation of various alkaloids by the acid solvent phase technic (atropine, cocaine, nicotine, sparteine, strychnine and corynanthine families). Boll. Soc. Chim. Biol. (Paris) 1951, 33, 846-856.

36. Jatzkewitz, H. A clinical method for determination of basic addiction drugs in urine. Hoppe-Seyler's Z. Physiol. Chem. 1953, 295, 94-100. [CrossRef]

37. Bessa, C.D.P.B.; Andrade, J.P.; Oliveira, R.S.; Domingos, E.; Santos, H.; Romão, W.; Bastida, J.; Borges, W.S. Identification of alkaloids from Hippeastrum. aulicum (Ker Gawl.) Herb. (Amaryllidaceae) using CGC-MS and ambient ionization mass spectrometry (PS-MS and LS-MS). J. Braz. Chem. Soc. 2017, 28, 819-830. [CrossRef]

38. Orhan, I.; Şener, B.; Kaiser, M.; Brun, R.; Tasdemir, D. Inhibitory activity of marine sponge-derived natural products against parasitic protozoa. Mar. Drugs 2010, 8, 47-58. [CrossRef] [PubMed]

39. Ellman, G.L.; Courtney, K.D.; Andres, V., Jr.; Featherstone, R.M. A new and rapid colorimetric determination of acetylcholinesterase activity. Biochem. Pharmacol. 1961, 7, 88-95. [CrossRef]

40. López, S.; Bastida, J.; Viladomat, F.; Codina, C. Acetylcholinesterase inhibitory activity of some Amaryllidaceae alkaloids and Narcissus extracts. Life Sci. 2002, 71, 2521-2529. [CrossRef]

41. Greenblatt, H.M.; Kryger, G.; Lewis, T.; Silman, I.; Sussman, J.L. Structure of acetylcholinesterase complexed with (-)-galanthamine at $2.3 \AA$ A resolution. FEBS Lett. 1999, 463, 321-326. [CrossRef]

42. Nachon, F.; Carletti, E.; Ronco, C.; Trovaslet, M.; Nicolet, Y.; Jean, L.; Renard, P.-Y. Crystal structures of human cholinesterases in complex with huprine $\mathrm{W}$ and tacrine: elements os specificity for anti-Alzheimer's grugs targeting acetyl- and butyryl-cholinesterase. Biochem. J. 2013, 453, 393-399. [CrossRef] [PubMed]

43. Cheung, J.; Rudolph, M.J.; Bushteyn, F.; Cassidy, M.S.; Gary, E.N.; Love, J.; Franklin, M.C.; Height, J.J. Structures of human acetylcholinesterase in complex with pharmacologically important ligands. J. Med. Chem. 2012, 55, 10282-10286. [CrossRef] [PubMed]

44. ChemCraft. Available online: http:/ / www.chemcraftprog.com/citation.htmL (accessed on 12 September 2017).

45. Adamo, C.; Barone, V. Toward reliable density functional methods without adjustable parameters: The PBE0 model. J. Chem. Phys. 1999, 110:13, 6158-6170. [CrossRef]

46. Petersson, G.A.; Benett, A.; Tensfeldt, T.G.; Al-Laham, M.A.; Shirley, W.A.; Mantzaris, J.; Mantzaris, J. A complete basis set model chemistry. I. The total energies of closed-shell atoms and hydrides of the first-row elements. J. Chem. Phys. 1988, 89, 2193-2218. [CrossRef]

47. Frisch, M.J.; Trucks, G.W.; Schlegel, H.B.; Scuseria, G.E.; Robb, M.A.; Cheeseman, J.R.; Scalmani, G.; Barone, V.; Mennucci, B.; Petersson, G.A.; et al. Gaussian 09, Revis. E.01; Gaussian, Inc.: Wallingford, CT, USA, 2013.

48. Moris, G.M.; Huey, R.; Lindstrom, W.; Sanner, M.F.; Belew, R.K.; Goodsell, D.S.; Olson, A.J. Autodock4 and AutoDockTools4: automated docking with selective receptor flexibility. J. Comput. Chem. 2009, 16, 2785-2791. [CrossRef] [PubMed]

49. Morris, G.M.; Goodsell, D.S.; Halliday, R.S.; Huey, R.; Hart, W.E.; Belew, R.K.; Olson, A.J. Automated docking using a Lamarckian genetic algorithm and an empirical binding free energy function. J. Comput. Chem. 1998, 19, 1639-1662. [CrossRef]

Sample Availability: Not available.

(C) 2017 by the authors. Licensee MDPI, Basel, Switzerland. This article is an open access article distributed under the terms and conditions of the Creative Commons Attribution (CC BY) license (http://creativecommons.org/licenses/by/4.0/). 